ORIGINAL ARTICLE

\title{
Pragmatic, observational study of bupropion treatment for smoking cessation in general practice
}

\author{
S Wilkes, A Evans, M Henderson, J Gibson
}

Postgrad Med J 2005;81:719-722. doi: 10.1136/pgmj.2005.032433

\begin{abstract}
See end of article for authors' affiliations

....................

Correspondence to: Dr S Wilkes, Centre for Primary and Community Care, School of Health Natural and Social Sciences, Benedict Building, St George's Way, University of Sunderland SR2 7BW, UK; scott.wilkes@sunderland. ac.uk
\end{abstract}

Submitted 11 January 2005 Accepted 6 March 2005
Background: Cigarette smoking remains the single largest cause of premature death in the United Kingdom. As part of the government's national service framework for coronary heart disease, smoking cessation forms a key part of the strategy.

Objectives: To determine the effectiveness of bupropion treatment for smoking cessation in a general practice setting, measuring continuous abstinence from smoking, from 8 weeks to 52 weeks.

Design: Prospective observational study.

Setting: One general practice (six whole time equivalent doctors, 11070 patients) in rural Northumberland.

Subjects: Of the 243 patients who presented to the practice over a one year period for smoking cessation, a total of 227 motivated people, who were appropriate for bupropion treatment as a pharmacological aid for smoking cessation, entered the study. Continuous smoking cessation at one year was validated by an exhaled carbon monoxide level of 10 ppm or less.

Results: Fifty patients successfully gave up smoking, giving a one year smoking cessation prevalence with bupropion of $22 \%$ (95\% confidence intervals $(\mathrm{Cl}) 17 \%$ to $28 \%$ ). There was no difference in success rate for sex, number of cigarettes smoked, the number of years smoking, or whether there were other smokers in the household or not.

Conclusion: Bupropion treatment in this general practice helped $22 \%$ of motivated people to quit and remain stopped smoking at one year. Mainly nurses, whose prescribing rights are restricted and currently exclude bupropion, deliver smoking cessation services in primary care.
C igarette smoking remains the single largest cause of premature disability and death in the United Kingdom.

The cost to the NHS is about $£ 1500$ million per year. ${ }^{1}$ In 1998 the UK government white paper on tobacco, Smoking Kills, ${ }^{2}$ suggested $£ 60$ million would be spent over a three year period to set up smoking cessation services.

In June 2000, bupropion was licensed, to help people to stop smoking in conjunction with motivational support. Bupropion is a non-nicotine based treatment that has been shown in two randomised, placebo controlled, double blind trials in the USA to be effective in helping smokers to stop with success rates between $23 \%$ and $30 \%$ at one year. This relates to the licensed dose of $300 \mathrm{mg}$ of bupropion daily for eight weeks together with professional follow up and support. $^{3}$ The National Service Framework (NSF) for Coronary Heart Disease, ${ }^{5}$ and the development of smoking cessation specialists, ${ }^{2}$ together with an extensive media campaign launch of bupropion provoked a need for primary care to integrate pharmacological and non-pharmacological support for people who wanted to stop smoking.

Smoking cessation rates sustained at one year are about 5\% for brief advice alone, ${ }^{6-8}$ up to $20 \%$ with counselling coupled with nicotine replacement therapy (NRT), ${ }^{6-9}$ and $20 \%-35 \%$ with bupropion. ${ }^{3}{ }^{4}$ 10-12

Our aim was to determine the effectiveness of bupropion for smoking cessation in a general practice setting, measuring continuous abstinence from smoking, from 8 to 52 weeks.

\section{METHOD}

\section{Setting}

This study took place in one general practice (six whole time equivalent doctors) in rural Northumberland, with a list size of about 11070 patients. Four practice nurses were trained in smoking cessation techniques. They offered support and pharmaceutical advice for the practice population.

\section{Subjects}

Patients between the ages of 18 to 75 years who presented to health care professionals for smoking cessation were included in the study. Exclusion criteria included a history of head injury, pregnancy, predisposition to seizures, current diagnosis or a history of anorexia nervosa or bulimia, liver cirrhosis, alcohol dependency, history of bupropion use within one year, a history of significant depression, bipolar disorder, or insulin dependant diabetes. Each patient was assessed on their motivation to stop smoking using the cycle of change. ${ }^{13}$ Those patients who showed they were at the "action" stage entered the study.

\section{Design}

A prospective observational study design was chosen. Patients presented to the smoking cessation specialist nurse either by self referral or via their GP over a one year period. Patients not eligible for bupropion treatment were offered alternative smoking cessation support, for example, NRT. Upon entry into the study, baseline information was obtained on age, sex, number of cigarettes smoked per day, number of years smoking, number of previous attempts to give up smoking, any previous use of NRT, any other smokers in the household, any history of concomitant disease, and measurement of the first exhaled carbon monoxide (CO) level. Bupropion, $150 \mathrm{mg}$ daily was taken for the first seven days and then $150 \mathrm{mg}$ twice daily for the remainder of the eight week treatment period. Follow up appointments with the

Abbreviations: $\mathrm{CO}$, carbon monoxide; NRT, nicotine replacement therapy 
Table 1 Distribution of concomitant disease

\begin{tabular}{ll}
\hline & Number of patients (\%) \\
\hline No concomitant disease & $171(75)$ \\
Asthma & $18(8)$ \\
Diabetes & $10(4)$ \\
Hypertension & $9(4)$ \\
Chronic obstructive pulmonary disease & $6(3)$ \\
Myocardial infarction/angina/coronary & $5(2)$ \\
artery bypass graft & $4(2)$ \\
Peripheral vascular disease & $4(2)$ \\
Other & \\
\hline
\end{tabular}

practice nurse occurred at 2, 4, 8, 26, and 52 weeks, each lasting 20 minutes and offering supportive advice and literature. Each visit recorded side effects, reasons for failing, and a CO level. CO levels of $10 \mathrm{ppm}$ or less validated abstinence from smoking. Failure to attend follow up was recorded as failed smoking cessation.

\section{Outcome measures}

The main outcome measure was continuous abstinence from smoking, from 8 weeks to 52 weeks. To achieve this, patients required a negative $\mathrm{CO}$ level at each follow up appointment.

\section{Analysis}

Data were analysed using Epi-info, ${ }^{14}$ and Minitab. Descriptive statistics were examined with comparison of dichotomous variables using $\chi^{2}$ with Yates's correction. A two sample $t$ test was applied where appropriate and a p value less than 0.05 was considered significant.

\section{RESULTS}

During the one year study period a total of 243 patients attended our practice for smoking cessation help. Five patients were unsuitable for bupropion treatment, as they were not at the "action" stage. ${ }^{13}$ Two patients had contraindications to bupropion treatment, two patients refused bupropion treatment, and seven patients specifically requested NRT in the form of patches. A total of 227 patients entered into the study for evaluation of bupropion treatment. The mean age of the patients was 43 years (SD 12 years). Forty seven per cent of patients presenting were men. The mean number of cigarettes smoked per day was 22 (SD 8) of which $19 \%$ were light smokers (less than 15 cigarettes per day). The mean number of years smoked was 26 years (SD 11 ). There were a median number of three (range 0-8) attempts at giving up smoking with $60 \%$ of patients having previously tried to stop with NRT. Of all smokers in the study $37 \%$ had one or more smokers living in their household. Twenty five per cent of patients had concomitant disease (table 1 ).

Fifty $(22 \%, 95 \% \mathrm{CI}, 17 \%$ to $28 \%)$ patients were nonsmokers at 52 weeks confirmed with CO validation (table 2).

Of those who failed to give up smoking, $132(58 \%)$ gave no reason, $36(16 \%)$ cited stress, $18(8 \%)$ cited side effects, 6

Table 2 Carbon monoxide validated smoking cessation at follow up $(n=227)$

\begin{tabular}{ll}
\hline Follow up (weeks) & Number (\%) \\
\hline 4 & $130(57)$ \\
8 & $98(43)$ \\
26 & $64(28)$ \\
52 & $50(22)$ \\
\hline
\end{tabular}

Table 3 Distribution of side effects experienced with bupropion

\begin{tabular}{ll}
\hline Side effect & Number (\%) \\
\hline None & $141(62)$ \\
Insomnia & $43(19)$ \\
Headache & $10(4)$ \\
Dry mouth & $5(2)$ \\
Dizziness & $5(2)$ \\
Nausea & $5(2)$ \\
Other & $18(8)$ \\
\hline
\end{tabular}

(3\%) cited depression, 5 (2\%) cited weight gain, 29 (13\%) gave another reason. Table 3 shows the distribution of side effects experienced by the study population.

Patients who were smokers for more than 25 years and hence in the older age groups were more likely to give up smoking although this did not reach significance (fig 1) (19 of 115 smokers $\leqslant 25$ years compared with 31 of 112 smokers $>25$ years; $\chi^{2}=3.5 ; p=0.06 ; 95 \%$ CI, 0.26 to 1.03 ). The mean age for those who had successful smoking cassation at one year was 46.3 years (SD 11.9) compared with 42.5 years (SD 11.9 ) for those who failed (mean difference 3.77 years; $95 \%$ $\mathrm{CI},-0.02$ to $7.56 ; \mathrm{p}=0.05)$. There was no difference in smoking cessation success when comparing men and women respectively ( 25 of 106 men compared with 25 of 121 women; $\chi^{2}=0.14 ; \mathrm{p}=0.71 ; 95 \% \mathrm{CI}, 0.43$ to 1.66$)$. Success was not predicted by the presence of concomitant disease ( 9 of 56 compared with 41 of $171 ; \chi^{2}=1.11 ; p=0.29 ; 95 \%$ CI, 0.24 to 1.40 ), the number of cigarettes smoked ( 31 of 138 smoking $\leqslant 20$ cigarettes/day compared with 19 of 90 smoking $>20$ / day; $\chi^{2}=0.01 ; p=0.94,95 \% \mathrm{CI}, 0.54$ to 2.20 ), or whether there were other smokers within the household (16 of 84 with smokers in the household compared with 34 of 143 with no smokers in the household; $\chi^{2}=0.44 ; \mathrm{p}=0.51 ; 95 \% \mathrm{CI}$, 0.36 to 1.53$)$.

\section{DISCUSSION}

\section{Main findings}

Continuous verified smoking abstinence from 8 weeks to 52 weeks was $22 \%$ (95\% CI, $17 \%$ to $28 \%$ ). Success or failure was not predicted by sex, number of cigarettes smoked per day, number of years smoking, the presence of concomitant disease, or if there were other smokers in the household.

\section{Strengths and weakness of the study}

This was a pragmatic study carried out in a busy general practice that has informed the smoking cessation strategy of our practice. The frequency and length of nurse appointments to deliver this service were both realistic and achievable. Our $22 \%$ success rate at one year must be viewed cautiously given that there were no comparison groups. Hence there was no evaluation of the direct effect that the four nurse consultations had over the one year study period.

\section{Comparison with other literature}

Bupropion was well tolerated by two thirds of the participants, with insomnia cited as the most frequent side effect followed by headache, dry mouth, dizziness, and nausea, which concur with the product datasheet. None of the 227 participants who received bupropion suffered a seizure or any other serious side effect. Two large European double blind randomised placebo controlled trials of $300 \mathrm{mg}$ bupropion daily for eight weeks showed a six month quit rate of $31 \%$ compared with $16 \%$ placebo (odds ratio $2.3,95 \%$ CL 1.4 to $3.7),{ }^{12}$ and a one year quit rate of $21 \%$ compared with $11 \%$ 


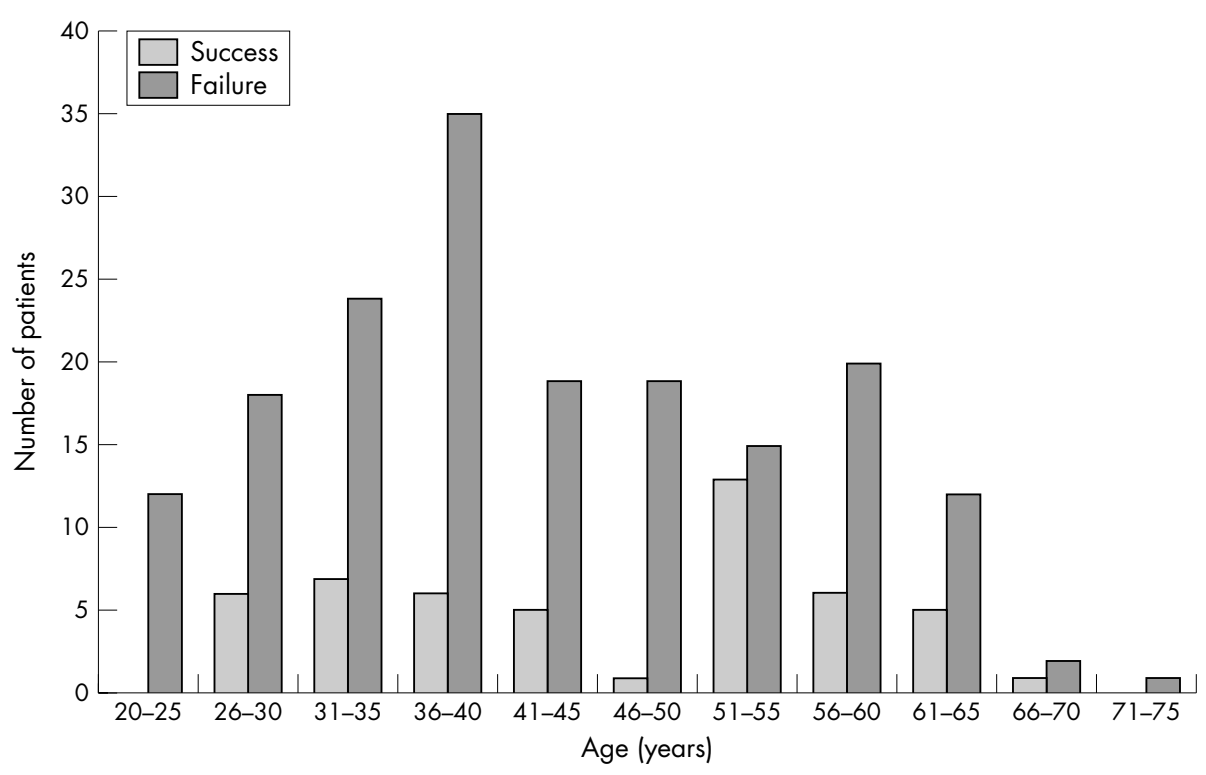

Figure 1 Age distribution of successful smoking cessation at 52 weeks.

placebo (odds ratio 2.2, $95 \mathrm{CL} 1.3$ to 3.8 ). ${ }^{11}$ A large randomised trial in the USA of $150 \mathrm{mg}$ to $300 \mathrm{mg}$ of bupropion daily for eight weeks showed one year quit rates of $24 \%$ to $33 \%$ respectively. ${ }^{10}$ A review of the evidence of effectiveness of bupropion treatment for smoking cessation in general practice found a six month point prevalent smoking cessation rate ranging from $25 \%$ to $49 \% .^{15}$ These data are comparable with our data from real life general practice. A systematic review of NRT and bupropion found both interventions effective for smoking cessation, however their relative effectiveness remains in doubt. ${ }^{16}$

\section{Implications for practice}

Despite an apparent increased efficacy of bupropion over NRT, NRT continues to be prescribed more than 10 times more often than bupropion. ${ }^{17}$ This may be because of the more favourable safety profile of NRT over bupropion. ${ }^{16}$ The demand for bupropion has decreased since its launch, probably because of media reports of the adverse effects of bupropion and NRT being available on prescription in the form of transdermal patches, chewing gum, and lozenges. Bupropion has been shown to be a successful aid for smoking cessation, ${ }^{3} 4^{10-12}$ and this study shows that bupropion treatment in a busy general practice setting may improve the one year smoking cessation rates by up to $22 \%$ and has informed the smoking cessation strategy of our practice. Currently, smoking cessation nurse specialists have limited prescribing rights and are unable to prescribe bupropion. Although this study may not be generalisable, a $22 \%$ success rate at one year would equate to 45000 quitters per year in the UK extrapolated from NHS statistics. ${ }^{17}$ Bupropion, where appropriate should be part of an overall smoking cessation strategy in primary care. ${ }^{18}$

\section{ACKNOWLEDGEMENTS}

The authors thank the helpful staff of Coquet Medical Group, Northumberland.

\section{CONTRIBUTORS}

SW ands AE were responsible for the study design. AE, MH, and JG recruited patients to the study and collected study data. SW, $\mathrm{AE}, \mathrm{MH}$, and JG contributed to the data analysis and writing of the paper. SW acts as guarantor of the study and accepts full responsibility for the conduct of the study, data access, and controlled the decision to publish.

\section{Authors' affiliations}

S Wilkes, Centre for Primary and Community Care, School of Health Natural and Social Sciences, University of Sunderland, UK

A Evans, M Henderson, J Gibson, Coquet Medical Group, Broomhill Health Centre, Morpeth, Northumberland, UK

Funding: the authors acknowledge a $£ 1000$ grant from the Northumberland Care Trust Smoking Cessation Strategy Group for their support and help with funding this project.

\section{Competing interests: none declared.}

Ethical approval: permission from Northumberland Local Research Ethics Committee for evaluation of this service implementation has been given.

\section{REFERENCES}

1 Royal College of Physicians of London. Nicotine addiction in Britain. A report of the tobacco advisory group of the Royal College of Physicians. London: $\mathrm{RCP}, 2000$.

2 Secretary of State for Health. Smoking kills: a white paper on tobacco. London: The Stationery Office, 1998.

3 Hurt RD, Sachs DL, Glover ED, et al. A comparison of sustained-release Bupropion and placebo. N Engl J Med 1999;337:1195-202.

4 Jorenby DE, Leischow SJ, Nides MA, et al. A controlled trial of sustainedrelease bupropion, a nicotine patch, or both for smoking cessation. N Engl J Med 1999;340:685-91.

5 NHS Executive. National service framework for coronary heart disease. London: NHS Executive, 1999

6 Muir J, Lancaster T, Jones L, et al. Effectiveness of health checks conducted by nurses in primary care: final results of the OXCHECK study. BMJ 1995;310:1099-104.

7 Wood DA, Kinmonth AL, Davies GA, et al. Randomised controlled trial evaluating cardiovascular screening and intervention in general practice: principal results of the British family heart study. BMJ 1994;308:313-20.

8 Austoker J, Sanders D, Fowler G. Smoking and cancer: smoking cessation. BMJ 1994;308:1478-82.

9 Raw M, McNeill A, West RJ. Smoking cessation guidelines for health care professionals. Thorax 1998;53(suppl 5):1-19.

10 Swan GE, McAfee T, Curry SJ, et al. Effectiveness of bupropion sustained release for smoking cessation in a health care setting. Arch Intern Med 2003; 163:2337-44.

11 Tonnesen P, Tonstad S, Hialmarson A, et al. A multicentre, randomised, double-blind, placebo-controlled, 1-year study of bupropion SR for smoking cessation. J Int Med 2003;254:184-92.

12 Aubin HJ, Lebargy F, Berlin I, et al. Efficacy of bupropion and predictors of successful outcome in a sample of French workers; a randomized placebocontrolled trial. Addiction 2004;99:1206-18.

13 Prochaska J, DiClimente C. Stages and processes of self-change of smoking: towards an integrative model of change. Journal of Counselling and Clinical Psychology 1983,51:390-5.

14 Dean AG, Dean JA, Burton AH, et al. Epi-info, version 5: a word processing, database and statistics program for epidemiology on microcomputers. Stone Mountain, GA: USD, 1990.

15 Holmes S, Zwar N, Jimenez-Ruiz CA, et al. Bupropion as an aid to smoking cessation: a review of real-life effectiveness. Int J Clin Pract 2004;58:285-91. 
16 Woolacott NF, Jones L, Forbes CA, et al. The clinical effectiveness and costeffectiveness of bupropion and nicotine replacement therapy for smoking cessation: a systematic review and economic evaluation. Health Technol Assess 2002;6:1-245

17 Department of Health. Statistics on NHS stop smoking services in England, April to September 2004. http://www.dh.gov.uk/
PublicationsAndStatistics/Publications/PublicationsStatistics/ PublicationsStatistics_Article/fs/en?CONTENT_ID $=4102867 \& \mathrm{chk}=6 \mathrm{GH} 8 \mathrm{hj}$ (accessed 10 Feb 2005)

18 West R, McNeill A, Raw M. Smoking cessation guidelines for health professionals: an update: Health Education Authority. Thorax 2000:55:987-99.

\section{Clinical Evidence-Call for contributors}

Clinical Evidence is a regularly updated evidence-based journal available worldwide both as a paper version and on the internet. Clinical Evidence needs to recruit a number of new contributors. Contributors are healthcare professionals or epidemiologists with experience in evidence-based medicine and the ability to write in a concise and structured way.

Areas for which we are currently seeking contributors:

- Pregnancy and childbirth

- Endocrine disorders

- Palliative care

- Tropical diseases

We are also looking for contributors for existing topics. For full details on what these topics are please visit www. clinicalevidence.com/ceweb/contribute/index.jsp

However, we are always looking for others, so do not let this list discourage you.

Being a contributor involves:

- Selecting from a validated, screened search (performed by in-house Information Specialists) epidemiologically sound studies for inclusion.

- Documenting your decisions about which studies to include on an inclusion and exclusion form, which we keep on file.

- Writing the text to a highly structured template (about 1500-3000 words), using evidence from the final studies chosen, within 8-10 weeks of receiving the literature search.

- Working with Clinical Evidence editors to ensure that the final text meets epidemiological and style standards.

- Updating the text every 12 months using any new, sound evidence that becomes available. The Clinical Evidence in-house team will conduct the searches for contributors; your task is simply to filter out high quality studies and incorporate them in the existing text.

If you would like to become a contributor for Clinical Evidence or require more information about what this involves please send your contact details and a copy of your CV, clearly stating the clinical area you are interested in, to CECommissioning@bmigroup.com.

\section{Call for peer reviewers}

Clinical Evidence also needs to recruit a number of new peer reviewers specifically with an interest in the clinical areas stated above, and also others related to general practice. Peer reviewers are healthcare professionals or epidemiologists with experience in evidence-based medicine. As a peer reviewer you would be asked for your views on the clinical relevance, validity, and accessibility of specific topics within the journal, and their usefulness to the intended audience (international generalists and healthcare professionals, possibly with limited statistical knowledge). Topics are usually 1500-3000 words in length and we would ask you to review between 2-5 topics per year. The peer review process takes place throughout the year, and out turnaround time for each review is ideally 10-14 days.

If you are interested in becoming a peer reviewer for Clinical Evidence, please complete the peer review questionnaire at www.clinicalevidence.com/ceweb/contribute/peerreviewer.jsp 